\title{
Digital Design Skills for Factories of the Future
}

\author{
Adrian Florea ${ }^{1, *}$ \\ ${ }^{1}$ Lucian Blaga University of Sibiu, Computer Science and Electrical Engineering Department, \\ 550025, 4 Emil Cioran, Sibiu, Romania
}

\begin{abstract}
Industry 4.0, Smart Manufacturing, Factories of the Future all describe aspects of the heralding era of digitalization of manufacturing aiming to interconnect every step of the manufacturing process and seamlessly integrate the physical and digital world. In Factories of the Future a central computer organizes the intelligent networking of all subsystems, suppliers and customers into one system. All relevant requirements concerning manufacturing and product are confirmed at design time, while execution takes place autonomously as ICT and automation are integrated. The main challenge is represented by educational system, how prepared is to provide students, future employees, the digital competences necessary for the Factories of the Future. What are the structural and curricular measures Higher Education Institutions need to take in order to align engineering education, especially in the design of all constituents of Factories of the Future, with the need of competences in new manufacturing era? A quantitative analysis of existing study programs aims understanding the status quo of Master programs in engineering education and, deriving from existing policy documents potential requirements for competences design of Factory of the Future employees.
\end{abstract}

\section{Introduction}

Digitalization of manufacturing and the Internet of Things (IoT) revolution in industrial sector is revealed by many new concepts like Industry 4.0, Smart Manufacturing, and Factories of the Future. They all describe, more or less, the ultimate goal which is to interconnect every step of the manufacturing process and seamlessly integrate the physical and digital world. The entire factory lifecycle from parts supply, operational efficiency, optimized manufacturing, quality assurance and delivery is supported by industrial Internet of Things, collaborative and autonomous guided robots. Thus, enterprises must consolidate their product and service development, production logistics and business systems to produce and deliver on a decentralized basis, in a self-directed way in real time. Researchers estimate that by 2020 IoT will impact close to $6 \%$ of the global economy [1]. The same study shows that $67 \%$ of questions from business leaders about digitalization relate to digital technologies: Smart sensors, IoT, Cyber Physical Systems (CPS), Big Data, Cloud computing, Data as a Services (DaaS), Connectivity, Machine Learning, Artificial Intelligence (AI) and Data Analytics. The role of software in the digital Factory of the

\footnotetext{
* Corresponding author: adrian.florea@ulbsibiu.ro
} 
Future, reconfigurable and extensible, becomes extremely important in every aspect of the value chain and shop floor. Therefore, it is necessary to model and implement serviceoriented scalable architectures that can be tailored to the specific needs of a company or a plant to capitalize on all the potential advantages of factory-related software components $[2]$.

In the context of digitalization we consider there are three kind of challenges: one which targets the companies (their strategy and management to revitalize existing manufacturing systems using hardware/software interconnected embedded systems, to optimize the factory floor and increase reliability, repeatability, and revenues), other which target the employees (and their personal interest for owning adequate digital skills needed for future jobs), and the last one aiming the educational system which should include in its curricula bachelor (BSc) and master (MSc) study programs which prepare students for the following jobs: Virtual Reality/Augmented Reality System Specialist, Digital Manufacturing Engineer, Digital Factory Automation Engineer, Chief Digital Officer [3].

Regarding the companies, the Business Models are changing to support digitalization. Innovative Business Models are based on crowdsourcing and collaboration among manufacturing stakeholders, who own different skills and expertise enabled and supported by new technologies [2]. However, they are facing some barriers in digital transformation: legacy complexity of software applications, cybersecurity concerns, and gaps for most of employers of IT (Information Technology) skills and competencies [1]. There are hurdles also in IT - Business interface: the lack of clarify on the meaning of digitalization, lack of long term strategy, outdated IT - Business collaboration models.

Although the digital transformation become mandatory in companies and despite of its challenges, companies can also taking advantages from the multiple opportunities offered by the fourth industrial revolution. In [4] the researchers highlight the following opportunities:

- Lower barriers between inventors and markets exploiting the advantage of new technologies such as 3D printing for prototyping

- Artificial Intelligence is gaining an increasingly important role in digital manufacturing solving complex problems offering new path to economic growth. IT research in manufacturing intelligence will assimilate the huge amount of data originating as a result of increased collaboration and connectivity and render meaningful information on-the-fly on mobile devices for managers and shop floor supervisors. The research efforts should be continue beyond the state of the art in complex event processing, realtime data analysis, and forecasting of complex scenarios originating in workplaces.

- Integration of different technics and domains, a fusion of technologies removes the lines between physical, digital, and biological spheres. Computer Science researchers call this age the Centaur Era (humans and computers working together) [5]. People are interacting with the physical world in completely new ways, with sensory input devices, smartphones, wearables, smart applications, cars, robots and computers augmenting reality to assist humans.

- Improving the productivity in industrial companies (using Collaborative Robots CoBots) and quality of daily lives (Humanoid Robots). Enhanced with AI and machine learning ability, robots have become smarter and more autonomous, tackling an increasing range of jobs that are dangerous for humans. The automation of production is accelerating around the world increasing from 66 robots in 2015 to 74 robot units per 10,000 employees (February 2018) being the new average of global robot density in the manufacturing industries.

- The connected life through Internet becomes familiar with clear social and commercial benefits outside of the scientific and engineering community. Wireless communication had become common, standardized, and successful with millions of access points 
deployed throughout the world. A number of standard communication and data exchange protocols had been developed and refined through widespread deployment. The IoT is expected to offer advanced connectivity of devices, systems, and services that goes beyond machine-to-machine (M2M) communications and covers a variety of protocols, domains and applications. Regarding the evolution of IoT, in 2014 were around 19.7 billion devices, and will head to 95.5 billion in 2025 .

Furthermore, technology is constantly evolving, and employees that do not keep their skills up-to-date will be overtaken at work by tasks and activities based on using new hardware devices and new software tools involving new functions, different abilities, and finally may lose their jobs. Companies cannot implement cutting-edge technologies if their workforce does not have the skills to use that new tech effectively. Without a critical mass of employees with appropriate digital skills, innovation will slow down. Yet industry needs new types of digital skills, which $90 \%$ of European enterprises indicate they lack, as 30-90 million manufacturing employees could lose their (semi)-manual jobs [6]. Although the artificial systems pose a threat to many kinds of employment digital transformation needs both IoT but also IoB (Internet of Brains). The International Federation of Robotics shows that over 1.8 million industrial robots worked in factories all over the world at the end of 2016 and predicts this figure to grow to over 3 million by the end of 2020. Globally, millions of jobs are disappearing due to automation, while at the same time millions of new jobs are being created. As more and more jobs are taken over by robots, human workers should be trained for more advanced positions in design, maintenance, and programming to keep up with technological evolution [7].

According with [8] who revealed a report of Vodafone Institute that surveyed 9,000 employees across nine countries, more than half $(56 \%)$ of employees worldwide said they do not have appropriate digital skills needed for future jobs. The report expressed the different vision of employees from three big countries of the world: USA, China and India. While the USA is the first in the IMD World Digital Competitiveness Ranking 2018, its employees do not feel prepared to handle with digital transformation from industry. $85 \%$ of respondents agreed that digital skills are necessities for their jobs, but only $29 \%$ of employees appreciated their skills as being currently strong enough. Specifically in the USA one of three employees said their companies provide them the opportunities or tools to continue gaining digital skills. The $26 \%$ of employees pointed out that companies should be responsible for teaching and developing workers' digital skills while other $24 \%$ considered the responsibility falls on the government to teach skills.

On the other side, in China, that is situated on 30th place in the same ranking, more than half $(53 \%)$ of respondents confirmed that they spend between one and five hours of their own time each week improving their digital skills, and 14\% of employees said they spend even longer. A high percent of employees (76\%) in China said that the companies provides them up to five or more hours of digital training each week and $83 \%$ of respondents from India report the same. As a consequence, the future can bring a strong competition between the USA, Asia and Europe both in the labour market and at educational level, and for staying relevant, Europe should invest heavily in the digital skills of its own population and in some strategic profiles, and corroborate it with political measures of motivating the workforce to not migrate and stay in Europe [9].

Digitalization requires that companies, Higher Education Institutions or other training institutions come together to develop skill profiles, trainings concepts as well as materials for design aspects of the Factory of the Future (FoF). 62\% in 2017 comparatively with 48\% in 2016, of the Human Resource managers admit that is difficult to keep up with the costs of training workers for future skills needs, especially that the dynamism of technological innovation generates new jobs that require new skills and working methods [10]. For example, none of the next 9 jobs did exist 10 years ago: (Big) Data Analyst, Drone Expert, 
App developer, Social media consultant, Salesforce Administrator, User Experience Expert, Vlogger/Blogger, Amazon Web Services Architect, Uber driver.

According to [11], Artificial Intelligence skills dominated the list of the fastest-growing jobs in 2018 and the trend is expected to grow in the future. Machines and algorithms are predicted to create 133 million new jobs by 2022, since companies are racing to adopt the technology that promises to revolutionize the way work gets done. The top 5 fastestgrowing jobs in 2018 requiring AI skills are: Blockchain Developer, Machine Learning Engineer, Application Sales Executive, Machine Learning Specialist, and Professional Medical Representative [11].

The impact of Artificial Intelligence in everyday life is ubiquitous from simply the comfort in smart homes to self-adaptive marketing, business intelligence in economic activities based on data analytics, clustering or prediction tools, but become crucial to the manufacturing function in automotive and manufacturing industry. In the following, we mention just three applications / tasks of smart manufacturing process which embeds machine learning algorithms but obviously the applicability of AI in manufacturing is much broader [12]:

- Computer Vision tools using machine learning algorithms trained to find microscopic defects in products like circuit boards or other.

- Evolutionary Algorithms (genetics) used in Generative Design and Optimization from multiobjective perspectives under different constraints (time, cost, space, etc).

- Predictive maintenance - used to predict the next failure of a part, machine or system

The main goal of this work is to propose an answer to the following questions: Romania is really prepared from educational system viewpoint for digitalization? And, in the context of digitalization what kind of competencies should future engineers have? What study programs might be proposed to support digitalization of manufacturing? Who do you think should do the professional training for students or employees in order to they get the necessary skills required by Factories of the Future?

In the next section, a perspective on European and Romanian Qualifications Framework as well as few studies on the job profiles, design of qualifications and skills required in the Factories of the Future. Section 3 is then dedicated to aspects concerning the research question and methodology of the analysis. Identified gaps are the focus of Section 4. Section 5 discusses themes that constitute avenues for further study, concluding the paper.

\section{Related work}

This section briefly describe how are currently reflected from national and European educational system viewpoint the jobs, design of qualifications and skills and what actions need to undertake in order to develop new qualifications required by digitalization era and enrol them in the education system. At European level exists the European Qualifications Framework (EQF) which is a translation tool helping in communication and comparison between qualifications systems from European countries. EQF is structured on eight reference levels described in terms of learning outcomes: knowledge, skills and competences. EQF ensure an unique reference level for any national qualifications frameworks (NQFs) and qualifications in Europe. This European framework helps also the learners, graduates, providers and employers who may compare qualifications awarded in different countries and by different education and training systems.

In Romania, the National Register of Qualifications in Higher Education (RNCIS) is aligned to European Qualifications Framework. Actually, each country owns its national qualifications framework (NQF) and relates it to EQF. Each specialization (study program) accredited and enrolled in RNCIS represents practically a qualification that has six professional and three transversal competences but which specifies the possible occupations 
the graduate can have. Competencies are clarified by level descriptors related to thematic content areas, taught topics, and related credit points. These are written on the diploma's supplement of each graduate of bachelor or master programs. In Romania, under Ministerial Order (OMECS) no. 5204/2014, all accredited study programs must register their competencies in RNCIS. Two examples of Master degree programs related to Industry 4.0 are "Automotive engineering-design, manufacture and development" implemented at University of Craiova and "Embedded Systems" implemented at Lucian Blaga University of Sibiu.

Unfortunately, at least at national level, the rapid transition to Industry 4.0 is not accompanied by an evolution of the Romanian educational system with the same rhythm. Education slowly advances from understanding the necessity of new study programs which offer qualifications specific to the digital factory of the future, up to the proposal of these qualifications, validation and enrolment in the National Register of Qualifications in Higher Education (RNCIS), the development of an accreditation file for a new study program.

Although the scientific literature contains enough examples aiming the need for new skills in the era of enterprise digitalization, are not many examples that address the issue at the stages level of realizing the curriculum of a new study program. In the following we present three studies on the job profiles, design of qualifications and skills required in the Factories of the Future. A German and American perspective about needs of the workforce and current challenges in Factories of the Future aiming to provide recommendation about qualifications and skills was done in [13] by an international team of engineers from diverse sectors of industry, government, and academia. Their approach of deriving qualifications and skills for the factory worker of the future consists of the analysis of three tiers. The base tier $\left(3^{\text {rd }}\right)$ includes factors like Tools and Technologies, Organization and Structure, Working Environment, Intra- and Inter-organizational cooperation. These factors determine Tasks $\left(2^{\text {nd }}\right.$ tier) of skilled labour. Finally, the Qualifications and Skills $\left(1^{\text {st }}\right.$ tier) derive from the existing Tasks. The authors classify in three categories (Must...Should...Could...) the skills of workers in a factory of the future that should be included in the skillset of the skilled labour from digitalization era.

In [14] the authors analyse the job roles in the companies of Industry 4.0 and identify the requirements for education and qualification of employees. Although most of their conclusions are general, the experimental part of their study involved a Czech company. The authors sustain that companies will have to exert maximum effort to help employees improve their skills and knowledge. However, they admit also the necessity of creation new, and changing the existing curricula and disciplines within tertiary education. Their approach illustrates the qualifications and skills needed for Information Technology (IT) job profile including Informatics Specialist, PLC Programmer, Robot Programmer, Software Engineer, Data Analyst, and Cyber Security and also for Production job role. The latest includes job like Electronics Technician, Automation Technician, Production Technician and Manufacturing Engineer.

The Organisation for Economic Co-operation and Development (OECD) Learning Framework 2030 represents an international project by government representatives and partners from academic, industrial and social environment which aims to find proper answers to the following questions: "What knowledge, skills, attitudes and values will today's students need to shape and thrive their world in 2030?" and "How can instructional systems develop these knowledge, skills, attitudes and values effectively?". It provides an informative vision and some underpinning principles regarding the future of education systems [15]. The most important concepts highlighted in their work refers to changing world (in domains like economic, social, environmental), the need for broader education goals (applying the long-life learning strategy), for a broad set of knowledge, skills, attitudes and values in action, competencies to transform the society and shape the future. 
These skills include cognitive and meta-cognitive skills like creative and critical thinking, learning to learn and self-regulation, soft skills like empathy, self-efficacy and collaboration and practical and physical skills such as using new information and communication technology devices. In the era of digital transformation and with the advent of big data the authors admit that the digital literacy and data literacy are becoming increasingly essential, as are physical health and mental well-being. The OECD Learning Framework 2030 encapsulates a complex concept: the mobilisation of knowledge, skills, attitudes and values through a process of reflection, anticipation and action, in order to develop the inter-related competencies needed to engage with the world.

\section{Research question and methodology of the analysis}

The research question that we approach in this section is the following: "In the context of digitalization what kind of competencies should future engineers have?"

The methodology used for the first bibliometric study involved the following stages:

1. Selection of the research criteria:

- Scientific articles listed in the Scopus database referring to the following keywords: 'Digital Design, Factories of the Future, Smart Manufacturing, Industry 4.0, Digital Transformation, and Robotics' in titles, keywords or abstracts.

2. Selection of a period and type of documents:

- Scientific articles published between 2000 and 2019.

3. Bibliometric analysis:

- Analysis of 2000 articles published in the Scopus database;

- The analysis included: the number of publications in the specified period and the most frequent keywords in research articles listed in the Scopus database.

4. Co-occurrences analysis:

- An analysis of the occurrence of key terms indicated by authors in the Scopus database and analysis of a map of current research trends, which shows the existing relationships between those keywords.

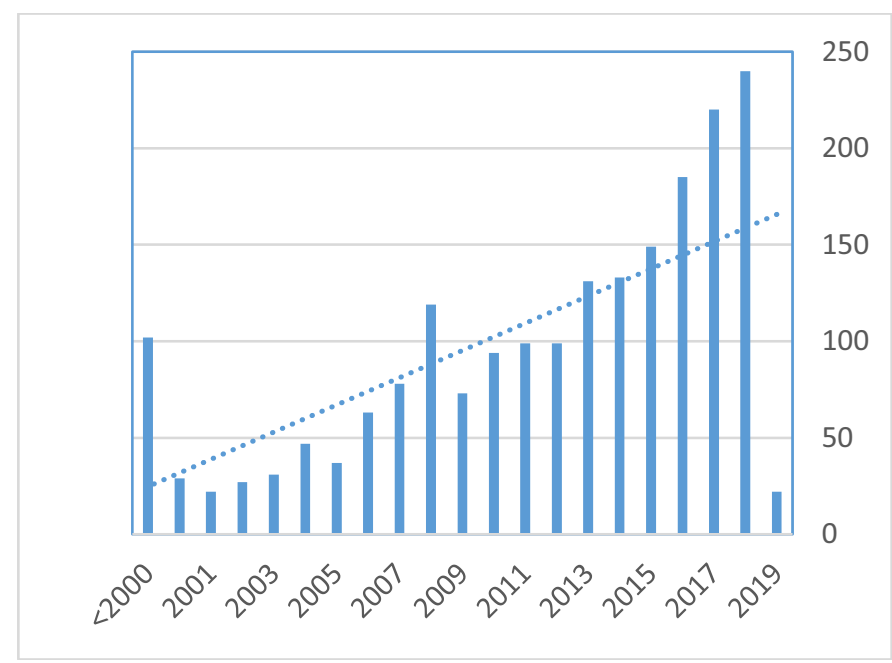

Fig. 1. Number of publications indexed in the Scopus databases referring to the concept of 'Digital Design, Factories of the Future, Smart Manufacturing, Industry 4.0, Digital Transformation, Robotics' (2000-2019). Source: elaborated by the author. 
Although only from 2008 the number of scientific papers exceeds 100, the popularity of publications aiming digitalization, indexed in Scopus databases is currently characterised by an upward trend. Because 2019 is just started the statistic for this year is incomplete. This chart emphasizes the digital transformation is no longer optional for companies but is indeed becoming mandatory.

Through this work we try to find whether the scientific terminology has been transmitted from the research level to education curricula.

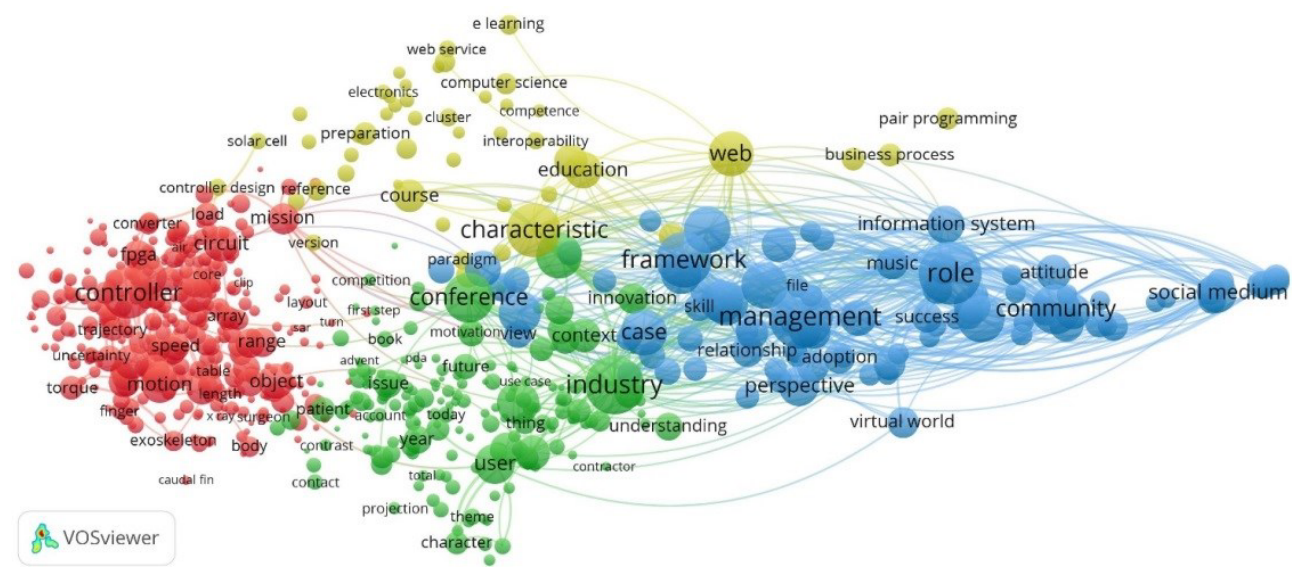

Fig. 2. Map of current research trends based on co-occurrence of the authors' keywords in publications referring to the concept of 'Digital Design, Factories of the Future, Smart Manufacturing, Industry 4.0, Digital Transformation, Robotics' from the Scopus database in the years 2000-2019, Source: authors own study using VOSviewer Software.

The VOSviewer (http://www.vosviewer.com) software represents a clustering tool which counts how often each keyword occurred within the database as well as how often the elements were cited together. Clusters are shown on the map in different colours. Four clusters of terms can be isolated, counting 658 words all together. The first cluster is centred on the terms of "control/er" - process, design, strategy, software, fuzzy, adaptive, microcontroller, FPGA, embedded systems and integrated approach but also digital tools like camera, model, converter, controller, simulator. The second cluster is composed of terms related to industries - robotic, manufacturing, aerospace, industrial revolution, Internet of Things (IoT) and Industrial IoT, Cyber Physical Systems, related to digitalization and digital processing techniques - production systems, fabrication, technology, innovation, paradigm, transformation, use cases, smart factory, augmented reality, virtual space and environments, infrastructure. Third cluster is organized around skills: engagement, attitude, role assumption, collaboration, relationship, management, planning, perspective (strategy), decision, and intelligence. The fourth cluster encloses topics like Education, (e-)learning, teaching, Electronics and Electrical Engineering, Mathematics, Economic and Business process, Communication Technology, Computer Science and subfields like Web design and services, Machine Vision, Data mining, Interoperability, Programming mobile devices, Real time applications.

\section{Identified gaps}

The analysis pertaining to the match of educational curricula versus research trends was done based on (1) the National Register of Qualifications in Higher Education, where the 
national competence profiles on Engineering curricula in Romanian universities are provided and (2) a web-search of Master programs at international level.

The aim was to identify - at Master level - (a) if the topics trending in research match with the topics provided in educational curricula, (b) what educational focus the study programs were addressing in terms of discipline as well as, (c) how the Romanian educational programs stacks up against international programs when looking for similar search criteria, i.e. keywords. It is worth mentioning, due to the lack of a formalized database of Master programs at international level, the comparison in (3) is only partial.

Striving to generate a database which was structured around comparable criteria, we performed the following tasks:

(a) The search in the National Register of Qualifications in Higher Education was limited to only those disciplines which address engineering as the competence addressed

(b) Out of those study programs selected in (a) only those were included in the analysis, which were not industry-specific. This means that study programs for chemistry-, naval, mining-, aero spatial-, nuclear-, and physics engineering were excluded. The reason for exclusion was twofold: (1) there was not enough data available in the research paper analysis to clearly distinguish between the topics and competences which are industryspecific and which are not, and (2) the number of study programs which could be found at national and international level was very low and the comparison would have been in part at individual program level.

(c) The search from (a) and (b) yielded a number of 23 study programs in Romania, which were analysed further according to the topics they are addressing.

(d) The web-search was performed on the same keywords as the Scopus database search, namely Digital Design, Factories of the Future, Smart Manufacturing/Industry 4.0, Digital Transformation, and Robotics. As all the Master-programs selected from the Romanian National Register of Qualifications in Higher Educations include only public education institutions as well as Master-programs at graduate level, we strived to be as accurate as possible in the comparative search. Thus, the web-search was limited to public universities or public universities of applied sciences, excluding professional or post-graduate Master programs. However, we did not limit the disciplines included in the search. The results were 60 Master-level study programs addressing one or more of the keywords above.

\subsection{Gaps between research and Romanian curricula}

To be able to build clusters and to compare these to the topics addressed by the research findings, each of the topics taught during the respective master programs, was checked and was added to one of the following categories:

(a) It addresses conceptual engineering activities like design, simulation, optimization, either on theoretical or on applied level (i.e. CAD-design)

(b) It addressed domain-specific systems like electromechanical systems, business systems, and information systems

(c) It addresses interdisciplinary topics pertaining to digitalization, digital transformation etc. linking two or more of the clusters identified in the Scopus analysis

(d) It addresses specific industrial technologies (like controller, circuits etc.) or instruments in the context of digitalization

Out of the 23 programs all had at least two courses addressing conceptual engineering activities like design, modelling and simulation/optimization (either on theoretical or on applied level). Depending on the domain they address this focuses either on product or process engineering or on the organizational management and optimization. While the topics do not focus around the term "controller" - in fact only in one of the Master-study 
programs, i.e. one of embedded systems controller design was addressed - conceptual engineering was present in the educational programs. However, what could be observed on a topical level was that no interdisciplinary design topics (e.g. product-service design or product-data-modelling etc.) were addressed. Similarly, each of the study programs contained at least three courses which addressed domain-specific focus topics, but less than $5 \%$ of the overall topics were specifically interdisciplinary. This is however different at program level, where out of the 23 programs 12 address one domain, 6 are interdisciplinary and 5 focus on transversal engineering topics without a specific domain-focus.

As for the last category, no specific course topic could be identified linking a technology directly to the topic of digitalization. There are several topics addressing technologies (i.e. like circuits, power stations, computer-aided design), however the syllabuses of these courses do not indicate that they address digitalization specifically.

What appeared in the research papers analysis, but is however completely lacking in the curricula analysed are topics like user experience design, communities development and planning (either from business or engineering perspectives), virtual and augmented reality, team-based cooperation mechanisms for innovation management, innovation technologies or concepts (like open innovation etc.). No such courses could be found in any of the 23 Master-programs selected.

\subsection{Gaps between research and international curricula}

The web-search for international Master-level programs relevant to the keywords in the Scopus search was restricted to such programs which contain the keywords in the program title. This was not intended to be an exhaustive search, but one which gives an indication if such programs exist, which disciplines and topics they address and where they are geographically located. It was mainly intended to understand if at international level the topics of Digital Transformation, Factories of the Future and Robotics have found their way in educational Master curricula.

Table 1. Digitalization specific topics included in Master Curricula.

\begin{tabular}{|c|c|}
\hline Keyword & No of Master programs \\
\hline Digital Transformation & 22 \\
\hline Digital Design & 12 \\
\hline Factories of the Future & 0 \\
\hline Smart Manufacturing / Industry 4.0 & 3 \\
\hline Digital Innovation & 21 \\
\hline Robotics & 5 \\
\hline
\end{tabular}

Out of the 63 programs found 22 are dealing with Digital Transformation, 12 with Digital Design, 3 with Smart Manufacturing/Industry and 5 with Robotics. Interestingly no program was addressing the topic of "Factories of the Future". This might be explained that, in Europe especially, the term coined by the European Union is used synonymously with the German initiative Industry 4.0, which has a wider recognition. However, during the search of terms which are included in the research cluster, 21 Master-level programs coined "Digital Innovation" appeared as a match and where thus included in the analysis.

With regard to the discipline studies addressed the distribution is as follows: 
Table 2. Digitalization specific topics reflected in Master Disciplines.

\begin{tabular}{|c|c|c|c|c|c|}
\hline \multirow{2}{*}{ Keyword } & \multicolumn{5}{|c|}{ Discipline study addressed } \\
\cline { 2 - 6 } & $\begin{array}{c}\text { Business / } \\
\text { Management }\end{array}$ & $\begin{array}{c}\text { Business and } \\
\text { Technology }\end{array}$ & $\begin{array}{c}\text { Science and } \\
\text { Science / } \\
\text { Technology }\end{array}$ & Technology & Design \\
\hline Digital Transformation & 12 & 0 & 8 & 2 & 0 \\
\hline Digital Design & 0 & 0 & 8 & 0 & 4 \\
\hline Factories of the Future & n.a. & n.a. & n.a. & n.a. & n.a. \\
\hline $\begin{array}{c}\text { Smart Manufacturing / } \\
\text { Industry 4.0. }\end{array}$ & 0 & 0 & 1 & 2 & 0 \\
\hline Digital Innovation & 6 & 1 & 14 & 0 & 0 \\
\hline Robotics & 0 & 0 & 5 & 0 & 0 \\
\hline
\end{tabular}

Business-oriented studies are focusing on the keywords "Digital Transformation" and "Digital Innovation", while Technology-oriented study programs focus on either "Smart Manufacturing/Industry 4.0" or on "Digital Transformation". However, it should be mentioned that the number of programs addressing technology solely is relatively low, i.e. 3 , in comparison to those addressing Science or Science/Technology, which is 36 . The allocation of the study program with regard to the discipline addressed has been taken of the website of each program. Thus, in general it can be seen that in the technology domain, which is typically that of engineering, a relative low number of programs address the topic even on international level.

Country-wise the most Master programs can be found in the United Kingdom (15), followed by Spain (6) and the United States and Australia (each with 5). France and Germany have each 4 Master programs addressing one of the selected topics of digitalization. Overall 16 countries have these types of programs, with the EU being the 17th with two inter-campus programs, which are distributed geographically. 13 of the 17 countries with these kinds of programs are from Europe, while 2 are from North America, 1 from Africa and 1 from Australia.

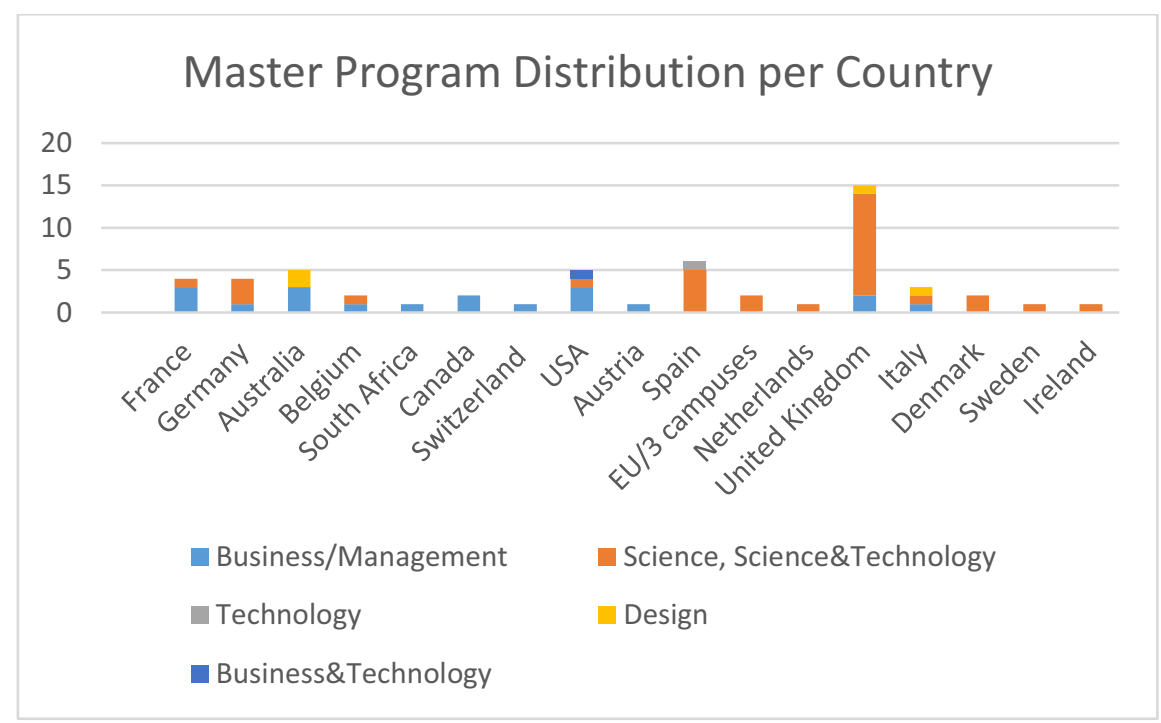

Fig. 3. Dominance of master categories in each country, Source: authors own study. 
With regards to the discipline of study addressed by the program a majority of $54 \%$ focuses on Science and Technology, followed by Business or Management programs with $34 \%$. Third in line are Design programs with mere 7\% while the pure Technology programs as well as the interdisciplinary Business and Technology programs trail the others with $2 \%$.

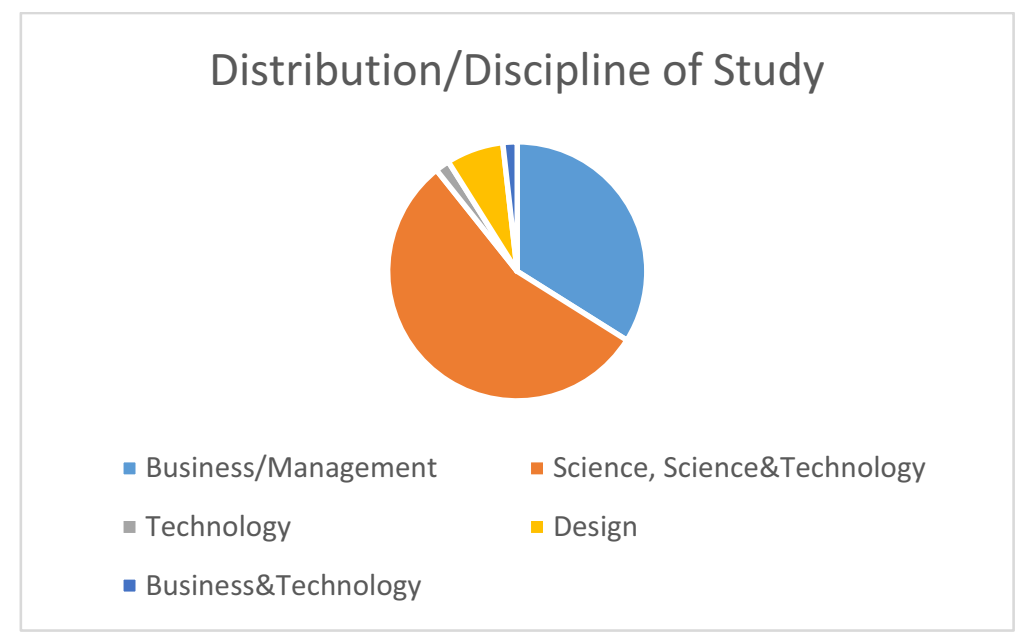

Fig. 4. Weights of disciplines of study addressed by Master Programs in Europe. Source: elaborated by the author.

Topics addressed within the study programs (independent of the discipline of study) focus strongly on design ranging from the creative, i.e. Design Thinking, up to the classic use of design in engineering for products and services. New topics in these digitalization programs are those of Analytics and Technology Transformation. Working ways like Agile, Critical Thinking are highlighted together with the classical topic of Leadership. Technologies like Big Data and Cloud are already included in curricula, while Artificial Intelligence has yet to find its way into teaching programs dealing with digitalization. Together with Design, Innovation is one of the most frequent topics addressed by the Master programs. Enterprise Architectures and Architectures in general are frequent in the curricula, differently to the topics addressed in the Romanian National Register of Qualifications in Higher Education. Data has emerged as one of the important topics in the digitalization programs. As of this selection programming is not a main topic in the study programs similarly to business process management/modelling, two classical topics from engineering disciplines. What the programs analysed are also missing are computer-aided design tools for the different digitalization topics. 


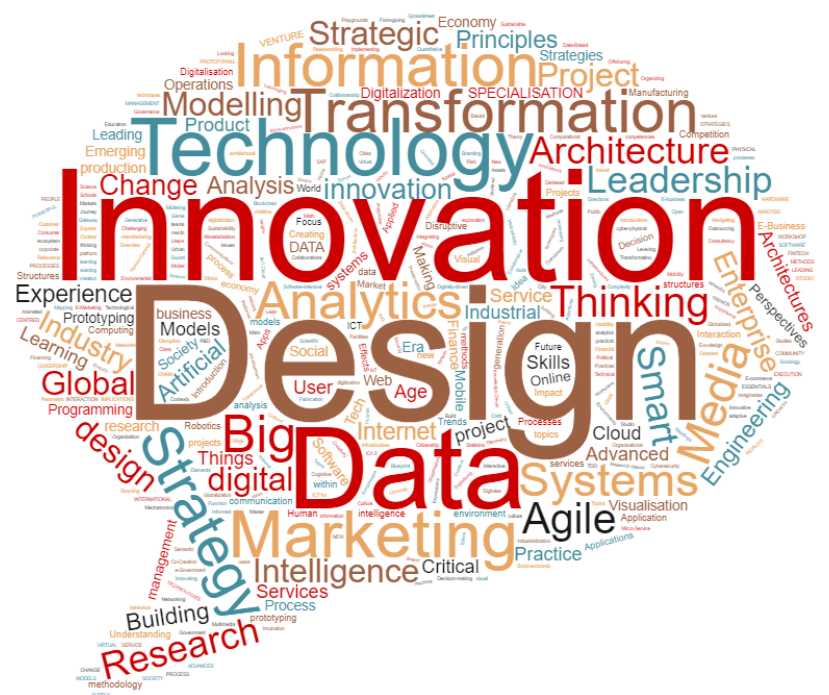

Fig. 5. Topics addressed by Master Programs in Europe, Source: elaborated by the author.

When comparing international programs with Romanian ones it can be seen that the latter have yet to address any specific topic of digitalisation, similarly to other European countries. These require not only a change of the curricula but also a consideration on how the suitable infrastructure (i.e. laboratories) should be shaped for the topics important in engineering during the digital transformation process of the economy.

\section{Conclusions and Further Work}

The message sent through this paper is of awareness the society, especially at the level of organizations and leaders from education, but also of the nowadays workforce about the need to adapt the own competences to the requirements of the society and the world economy based on digitalization. In this work we have shown that the popularity of digitalization concepts is currently characterised by an upward trend but also, the educational system is not prepared yet with curricula to support the new jobs created by digitalization. The most important conclusion refers to the necessity to accelerate the generation of curricula for qualifications and competencies specific for Factories of the Future.

From the perspective of the study programs that provide classical engineering skills, Romania is positioned quite well but did not bother yet to include in the curriculum relevant topics for digitalization to the difference from other European countries. So there is a need for adapted curricula (at the engineering level but not only) with the inclusion of new topics and disciplines. Europe should continue to invest in training programs for workers at risk of losing their jobs. It should also invest in digital skills to remain competitive, prioritizing machine learning, information security, design thinking, problem based learning, system design in a holistic way that integrates business and technology issues in the final product.

As further work, we intend to apply to different calls for national and European projects aiming to mitigate some of the identified gaps by creating a network of interconnected laboratories across Europe equipped with corresponding materials and tools in order to build up an educational ecosystem for Factory of the Future design. In addition it will 
create an organizational platform for knowledge and staff exchange between industry and academia.

\section{Acknowledgements}

This work was partially developed under the ERASMUS+ KA2 project "THE FOFDESIGNER: DIGITAL DESIGN SKILLS FOR FACTORIES OF THE FUTURE”, financing contract no. 2018-2553 / 001-001, project number 601089-EPP-1-2018-1-ROEPPKA2-KA, web: http://www.digifof.eu.

\section{References}

1. J. Hase, The Role of IoT in your Digital Transformation Journey, unlimit - A Reliance Group Company (2018), https://dta.tmforum.org/wp-content/uploads/2018/11/2.-201811-14-The-Role-of-IoT-Unlimit.pdf

2. Factory of the Future, White Paper, IEC, http://www.iec.ch/whitepaper/futurefactory/, accessed on January $3^{\text {rd }}(2018)$

3. I. Maw, 5 Future Jobs that Could Solve the Manufacturing Skills Gap (2017), https://www.engineering.com/AdvancedManufacturing/ArticleID/15520/5-FutureJobs-that-Could-Solve-the-Manufacturing-Skills-Gap.aspx

4. M. Xu, M. David, H. Kim (2018), The Fourth Industrial Revolution: Opportunities and Challenges. International Journal of Financial Research. 9. 90. 10.5430/ijfr.v9n2p90.

5. M. Duranton, K. De Bosschere, C. Gamrat, J. Maebe, H. Munk, O. Zendra, Duranton, M. The HiPEAC Vision 2017. Available online: https://www.hipeac.net/vision/2017/ (accessed on December 31st 2018).

6. European Commission, Upskilling European Industry: New operational tools wanted, http://ec.europa.eu/social/main.jsp? catId=1224, accessed on February 11th, (2018)

7. Robots and the Workplace of the Future, A positioning paper by the International Federation of Robotics (IFR) (2018), Frankfurt, Germany, https://ifr.org/downloads/papers/IFR_Robots_and the Workplace_of the Future_Posi tioning_Paper.pdf

8. M. Bayern, $56 \%$ of employees lack digital skills needed for future jobs, Digital Transformation (2019), TechRepublic, https://www.techrepublic.com/article/56-ofemployees-lack-digital-skills-needed-for-future-jobs/, accessed on March 4th (2018)

9. M. Duranton, K. De Bosschere, B. Coppens, C. Gamrat, M. Gray, H. Munk, E. Ozer, T. Vardanega, O. Zendra, HiPEAC Vision 2019: the future of computing, Available online: https://www.hipeac.net/vision/\#/ (accessed on March 15th 2019).

10. D. McCafferty, Why Your Employees May Be Looking for a New Job, ACM Career News (2017), http://www.cioinsight.com/it-management/careers/slideshows/why-youremployees-may-be-looking-for-a-new-job.html, accessed June 6th 2017.

11. M. Bayern, AI skills reign supreme in the fastest-growing jobs of the year, CXO (2018), TechRepublic, https://www.techrepublic.com/article/the-top-5-ai-jobs-for2019/, accessed on March $4^{\text {th }}(2018)$

12. How AI Builds a Better Manufacturing Process, FORBES INSIGHTS (2018), https://www.forbes.com/sites/insights-intelai/2018/07/17/how-ai-builds-a-bettermanufacturing-process/\#5b3cba7b1e84, accessed on March $1^{\text {st }}(2018)$

13. L. Gehrke, T. Kühn, Arno, D. Rule, P. Moore, C. Bellmann, S. Siemes, D. Dawood, L. Singh, J. Kulik, M. Standley, (2015). Industry 4.0 - A Discussion of Qualifications and Skills in the Factory of the Future: A German and American Perspective, Hanover Conference, Germany, VDI Verein Deutscher Ingenieure e.V. / ASME. 
14. A. Benešová, J. Tupa. Requirements for education and qualification of people in Industry 4.0. Procedia Manufacturing, 11, 2195-2202 (2017)

15. A. Schleicher, The future of education and skills Education 2030, Organisation for Economic Co-operation and Development (OECD), https://www.oecd.org/education/2030/E2030\%20Position\%20Paper\%20(05.04.2018).p $\underline{\mathrm{df}}$ 